\title{
Music Listening Habits and Music Perception Abilities of Prelingually Deafened Adolescent Cochlear Implant Recipients
}

\author{
Mustafa Yüksel, $\mathrm{PhD}^{1,2}$ Atılım Atılgan, $\mathrm{PhD}^{3}$ Ayça Çiprut, $\mathrm{PhD}^{3}$ \\ ${ }^{1}$ Audiology and Speech Disorders Program, Institute of Health \\ Sciences, Marmara University, İstanbul, Turkey \\ 2 Department of Speech and Language Therapy, School of Health \\ Sciences, Ankara Medipol University, Ankara, Turkey \\ ${ }^{3}$ Audiology Department, Marmara University Faculty of Medicine, \\ İstanbul, Turkey \\ J Am Acad Audiol 2020;31:740-745. \\ Address for correspondence Mustafa Yüksel, PhD, \\ mustafa.yuksel@ankaramedipol.edu.tr
}

\begin{abstract}
Keywords

- cochlear implants

- music perception

- listening habits

- adolescent

Background Music is a very important art form that can evoke strong emotions and involvement with it can have a considerable impact on cochlear implant $(\mathrm{Cl})$ recipients' quality of life. It is well known that music perception is limited in $\mathrm{Cl}$ with fully electric hearing and $\mathrm{Cl}$ recipients have significantly poorer music-appraisal ability when compared with normal hearing subjects. Considering the importance of music on the life of an adolescent and negative impact of hearing loss on mental health, understanding and improving music listening habits and perception abilities can have a positive impact on the mental health of $\mathrm{Cl}$ user adolescents.

Purpose This study aims to evaluate music listening habits and music perception abilities of prelingually deafened adolescent $\mathrm{Cl}$ users to reveal the relationship between self-reported assessment and psychophysical measurement.

Research Design The psychophysical measures of music perception and self-reported music listening habits of adolescent $\mathrm{Cl}$ users were obtained.

Study Sample Twenty-nine prelingually deafened adolescent $\mathrm{Cl}$ users were evaluated in this study.

Data Collection and Analysis The Turkish Clinical Assessment of Music Perception (TCAMP) test was used to evaluate music perception abilities. These abilities were evaluated with a three-item questionnaire assessing enjoyment of music, listening habits, and comprehension of lyrics. Pearson's correlation coefficients were calculated to assess the relationship between the T-CAMP subtests and questionnaire items.

Results Statistically significant correlations were observed between the melody-recognition subtest of T-CAMP and all three questionnaire items. The correlation between the enjoyment and rate items on the questionnaire was also statistically significant.

Conclusion The present study shows that adolescent $\mathrm{Cl}$ users also enjoy and listen to music in ways similar to postlingually deafened adult $\mathrm{Cl}$ users. It also demonstrates that melody-recognition abilities have a significant relationship with music enjoyment and listening habits in prelingually deafened adolescent $\mathrm{Cl}$ users.
\end{abstract}

received

January 20, 2020

accepted after revision

April 10, 2020

published online

December 15, 2020
(C) 2020. American Academy of

Audiology. All rights reserved.

Thieme Medical Publishers, Inc.,

333 Seventh Avenue, 18th Floor,

New York, NY 10001, USA
Dol https://doi.org/

10.1055/s-0040-1719132. ISSN $1050-0545$. 
Although cochlear implantation $(\mathrm{CI})$ can restore hearing and improve speech perception in patients with severe and profound hearing loss, other important aspects of hearing should also be restored. Among these aspects is music perception. Music is an important art form that can evoke strong emotions, ${ }^{1}$ and involvement with it can have a considerable impact on CI recipients' quality of life. ${ }^{2}$ However, music perception is limited in CI with fully electric hearing ${ }^{3-6}$ as a result of limited spectral sensitivity and slow varying temporal envelopes. ${ }^{7}$

However, music involves personal and cultural variables, so the psychophysical measures of music perception may not reflect the subjective appreciation and music listening habits of $\mathrm{CI}$ recipients. The music appraisal ability of $\mathrm{CI}$ recipients is significantly poorer than that of subjects with normal hearing $^{8,9}$ and the recipients themselves prior to hearing loss. ${ }^{10,11}$ Gfeller et $\mathrm{al}^{12}$ evaluated 209 adult CI users and found that neither device type nor processing strategy can predict the accuracy of music perception. Speech perception abilities, music listening history, residual hearing, and cognitive factors can be used to predict some aspects of musical appraisal, but the predictive powers of measured variables are generally weak. Philips et $\mathrm{al}^{13}$ showed a statistically significant correlation between speech perception abilities, music enjoyment, and finding music with the $\mathrm{CI}$ sounding more natural in $15 \mathrm{CI}$ users, although $\mathrm{CI}$ users with good and poor speech perception abilities describe the importance of music in their life with respect to their own well-being and social life. Wright and Uchanski ${ }^{14}$ evaluated $10 \mathrm{CI}$ users by using the Appreciation of Music in Cochlear Implantees, the Montreal Battery of Evaluation of Amusia, Melodic Contour Identification, and the University of Washington Clinical Assessment of Music Perception (UW-CAMP) tests. Drennan et $\mathrm{al}^{15}$ examined $145 \mathrm{CI}$ users by utilizing the UW-CAMP test and the Iowa Musical Background Questionnaire. Both studies have demonstrated that correlations between musical appraisal and perception scores are weak or nonexistent. These studies have also emphasized that music perception skills and musical appraisal do not always coincide, and both domains need further improvement.

Although previous studies examined different aspects of music in the life of $\mathrm{CI}$ users in a broad sense, music can have different social and psychological impacts on people at different developmental periods. ${ }^{16}$ This impact is significant in the contemporary lives of adolescents who live in a new media age and listen to a considerable amount of music daily. ${ }^{17}$ Adolescence is an important period of changes, challenges, and identity reconstruction; in this complex period, adolescents experience serious stress and anxiety. ${ }^{18}$ Music can be an important tool to cope with stress because it can influence emotions and mood and reflect the emotional turbulence experienced by adolescents. ${ }^{19,20}$ Moreover, music should not always be considered a passive listening activity; in many instances, adolescents can participate in music by singing, playing an instrument, and dancing. Participating in music has a positive influence on anxiety and depression $^{21}$ and is related to a high quality of life and satisfaction with health. ${ }^{22}$ Therefore, how adolescent CI users listen to music should be understood in terms of listening frequency, enjoyment, and perception. This under- standing can help hearing professionals develop awareness on the positive impact of music on the mental health of adolescent $\mathrm{CI}$ users in consideration of the negative impact of hearing loss on mental health. ${ }^{23,24}$

To our knowledge, only one study has focused on the music perception abilities of adolescents. Driscoll et $\mathrm{al}^{25}$ evaluated and compared the music perception abilities of adolescents by using electroacoustic hearing, children and adolescent CI recipients with traditional $\mathrm{CI}$ electrodes, and a control group of children with normal hearing. The performance of the electroacoustic CI group is better than that of the traditional CI group and similar to that of subjects with normal hearing in terms of pitch ranking, melodic error detection, and melody recognition tests on music perception. However, with the benefits of electroacoustic hearing, researchers cannot easily present a conclusion that considers the age of participants. Few studies have also evaluated smaller age groups. Jung et $\mathrm{al}^{26}$ examined the music perception abilities of prelingually deafened pediatric $\mathrm{CI}$ recipients aged 8 to 16 years and compared their findings with those of a similar previous study involving adult CI recipients. ${ }^{27}$ The pitch discrimination subtest performance is not significantly different between groups, but the melody and timbre recognition scores of pediatric $\mathrm{CI}$ recipients are worse than those of adult $\mathrm{CI}$ recipients; the melody recognition performance of participants is also below the chance level. Yüksel et $\mathrm{al}^{28}$ analyzed pediatric $\mathrm{CI}$ recipients aged 9 to 13 years with very good residual hearing and found that the performance of participants is similar to that of subjects with normal hearing in the pitch discrimination test.

To describe the relationship between the musical appraisal and music perception abilities of adolescent $\mathrm{CI}$ users in detail, we aimed to evaluate music listening habits with a self-reported numeric rating scale and examine music and speech perception abilities with psychoacoustic measurements. We believed that we could comprehensively investigate the significance of music in the life of a teenage $\mathrm{CI}$ user by using both methods.

\section{Materials and Methods}

\section{Participants}

Twenty-nine prelingually deafened CI user adolescents (13 males and 16 females) were involved in this study. Patients who received implants between 2003 and 2018 were examined, and patients who met the inclusion criteria were recruited. The inclusion criteria were as follows: having severe-to-profound hearing loss before the age of 60 months, more than 1 year of $\mathrm{CI}$ use, age between 12 and 18 years during the test, and normal auditory nerve and cochlear anatomy. All the subjects were able to orally communicate and gain speech perception scores after $\mathrm{CI}$ use (monosyllabic word recognition score range $=96-66 \%$ ). Subjects were excluded if they had any formal music education beyond regular music lessons in grade school or additional mental and neurological disorders, including auditory neuropathy spectrum disorder. The detailed information of the CI recipients is listed in - Table 1. Their age upon diagnosis, implantation, and testing were also recorded. 
Table 1 Demographic variables of study participants

\begin{tabular}{|c|c|c|c|c|c|}
\hline $\begin{array}{l}\text { Age } \\
\text { (y) }\end{array}$ & $\begin{array}{l}\mathrm{HL} \\
\text { age } \\
\text { (mo) }\end{array}$ & $\begin{array}{l}\mathrm{Cl} \\
\text { age } \\
\text { (mo) }\end{array}$ & Bimodal & Device & Processor \\
\hline 12 & 6 & 24 & No & $\mathrm{Cl} 24 \mathrm{RE}$ & CP1000 \\
\hline 17 & 12 & 24 & No & Pulsarci100 & Sonnet \\
\hline 15 & 6 & 36 & No & $\mathrm{CI} 24 \mathrm{RE}$ & CP910 \\
\hline 16 & 6 & 42 & No & $\mathrm{Cl} 24 \mathrm{RE}$ & CP910 \\
\hline 13 & 6 & 48 & No & CI24R(CS) & CP910 \\
\hline 17 & 6 & 48 & No & Sonataci100 & Opus 2 \\
\hline 18 & 42 & 48 & No & $\mathrm{Cl} 24 \mathrm{RE}$ & CP810 \\
\hline 16 & 18 & 49 & No & CI24RE & CP910 \\
\hline 18 & 42 & 57 & No & CI24RE & CP950 \\
\hline 18 & 12 & 60 & No & CI24RE & CP950 \\
\hline 18 & 12 & 72 & No & CI24RE & CP950 \\
\hline 17 & 6 & 78 & No & $\mathrm{Cl} 24 \mathrm{M}$ & CP950 \\
\hline 15 & 8 & 78 & No & $\mathrm{Cl} 422$ & CP810 \\
\hline 12 & 42 & 84 & No & Concerto & Opus2 \\
\hline 18 & 60 & 90 & No & CI24RE & CP910 \\
\hline 17 & 18 & 96 & Yes & CI24RE & CP910 \\
\hline 14 & 6 & 24 & Yes & CI24RE & CP950 \\
\hline 13 & 50 & 84 & No & CI24RE & CP950 \\
\hline 14 & 6 & 36 & No & $\mathrm{Cl} 24 \mathrm{RE}$ & CP810 \\
\hline 13 & 48 & 70 & No & $\mathrm{Cl} 422$ & CP810 \\
\hline 13 & 24 & 60 & No & $\mathrm{Cl} 24 \mathrm{R}(\mathrm{CS})$ & CP950 \\
\hline 15 & 12 & 36 & Yes & CI24RE & CP810 \\
\hline 18 & 11 & 38 & No & CI24RE & CP810 \\
\hline 15 & 40 & 84 & Yes & CI24RE & CP950 \\
\hline 16 & 42 & 90 & Yes & CI24RE & CP910 \\
\hline 16 & 12 & 48 & Yes & CI24RE & CP910 \\
\hline 18 & 18 & 60 & Yes & CI24RE & CP810 \\
\hline 18 & 48 & 96 & No & $\mathrm{CI} 24 \mathrm{RE}$ & CP810 \\
\hline
\end{tabular}

Abbreviations: $\mathrm{Cl}$, cochlear implantation; $\mathrm{HL}$, hearing loss.

The music perception abilities of the subjects were evaluated with the Turkish version of the Clinical Assessment of Music Perception (T-CAMP) test. ${ }^{29}$ Music listening habits were evaluated using a three-item 11-point scale developed for this study.

The protocol of this study was approved by the ethics committee, and informed written consent was obtained from all the subjects and their parents (for subjects under 18 years of age).

\section{Procedure}

T-CAMP and speech perception tests were conducted in a double-walled audiometric booth (Industrial Acoustics Company Inc., USA) during the same session. Sound intensity was set at $65 \mathrm{~dB}$ A for T-CAMP testing, and a custom-made MATLAB (MathWorks Inc., Matick, MA) program was used to present stimuli on a computer connected to a Madsen
Astera audiometer (Otometrics, Natus Medical, Denmark) with a single JBL Control One loudspeaker (JBL, Harman International, USA) positioned at $1 \mathrm{~m}$ distance with 0 degrees azimuth and elevation from the participants. The $\mathrm{CI}$ users were evaluated using the same open-set monosyllable word list. Word recognition scores were obtained with a monitored live voice and calculated by counting the number of a $\mathrm{CI}$ user's correctly repeated words, dividing this number by the total number of words, and multiplying the result by 100 .

\section{Musical Appraisal and Listening Habits}

Musical appraisal and listening habits were evaluated with three questions. For the first two questions, 11-point numeric rating scales with opposite adjectives and numeric response descriptors were used. Studies have described the use of 5-, 7-, $10-$, or 11 -point scales in questionnaires ${ }^{30}$ and suggested that an 11-point scale can minimize categorization effects, improve data analysis, and minimize measurement errors. ${ }^{31}$ Therefore, an 11-point numeric rating scale with a real midpoint was chosen to conduct detailed measurements in this study.

The three items pursued in the scale were enjoyment of music, lyric comprehension, and listening habits. The following enjoyment item question was asked to understand musical appraisal: "How much do you enjoy listening to music?" A rating of 0 was given for "not at all," and 10 was given for "to a great extent."

For the lyrics, the question was "Can you understand the lyrics of a song that you listen to?" Understanding lyrics in music can help CI recipients compensate for poor pitch, melody, and timbre recognition and improve their ability to recognize melodies ${ }^{4}$; therefore, measuring lyric comprehension with self-reported measures could also be helpful.

For listening habits, the question was "How often do you listen to music?" Scoring was made on a rating scale of 0 to 10: $0=$ never, $2=$ once a month, $4=$ few times a month, $6=$ once a week, $8=$ a few times a week, and $10=$ every day.

\section{T-CAMP}

T-CAMP testing was performed in accordance with the procedure previously described by Nimmons et al $^{6}$ and Yüksel and Çiprut. ${ }^{29}$ Each subtest was initiated with short training sessions. In these sessions, the subjects were asked to listen to 4 different pitch pairs, 12 melodies, and 8 instruments twice. The pitch direction discrimination (PDD) subtest was preserved, but melody and timbre recognition tests were modified for Turkish listeners.

In the PDD subtest, a two-alternative forced choice was used: one-up and one-down adaptive procedures. Synthesized complex tones with a 760-ms duration were used. Two buttons (labeled as one and two) were presented on a computer screen, and the subjects were instructed to select the button corresponding to the tone with a higher pitch. Testing began with four practice intervals, including feedback, but no feedback was given to the subjects in the actual testing. Three base frequencies were set $(262 \mathrm{~Hz}, \mathrm{C} 4 ; 330 \mathrm{~Hz}, \mathrm{E} 4$; and $392 \mathrm{~Hz}, \mathrm{G} 4)$, and the interval of the higher pitch tone was changed between 1 and 12 semitones. The initial pitch pair had an interval of 12 semitones. Each correct response was followed by a smaller 
interval, and each incorrect response was followed by a larger interval. Every incorrect response after a correct response was defined as a reversal, and a PDD threshold for each base frequency was calculated from the mean pitch interval in semitones by using the last six of the eight reversals. The mean of the three base frequencies was determined to arrive at the final PDD score.

In the melody recognition subtest, previously selected and tested 12 melodies were used. ${ }^{29}$ All the melodies were played isochronously to eliminate rhythm cues with synthesized notes for $500 \mathrm{~ms}$ in an 8-note pattern at a tempo of 60 beats per minute. Five versions of each melody were prerecorded with different note intensities $( \pm 4 \mathrm{~dB})$, and a different version was played randomly at each time to avoid intensity cues. The total melody recognition score was calculated after 36 presentations.

In the timbre recognition test, eight musical instruments, namely, a Turkish saz, a piano, a guitar, a violin, a trumpet, a flute, a clarinet, and a saxophone, were used. All instruments were played with the same five-note sequence with the same articulation, duration ( 5 seconds), phrasing, and mezzo-forte intensity and recorded in a professional studio environment with professional musicians. The amplitudes of the instruments were normalized using root mean square, followed by peak normalization. Total timbre recognition was calculated after 24 presentations.

\section{Statistical Analysis}

Statistical analysis was performed using SPSS 21.0 (SPSS Inc., Chicago, IL). Descriptive statistics (mean, media, standard deviation, range, and interquartile range) were used to describe study variables. Histograms and Shapiro-Wilk normality test were utilized to assess the normal distribution of means. Spearman's correlation coefficients were calculated to analyze the relationship between numeric rating scale scores and T-CAMP subtests. A 0.05 significance level was set.

\section{Results}

The question responses, PDD, melody recognition, and timbre recognition scores are presented in -Table 2.
Melody recognition was significantly correlated with three-scale items ( $p<0.05$; - Table 3 ). However, no statistically significant correlation between other T-CAMP measures and scale items was observed.

Enjoyment and rate items showed statistically significant correlations ( $p<0.05$; - Table 4).

\section{Discussion}

\section{T-CAMP and Scale}

Our findings showed that the self-reported measurements of music were related to psychophysical ones. The most striking finding was the relationship between melody recognition and music enjoyment. Melody is arguably the most prominent musical feature of modern rhythmic music and has been used in different studies to evaluate the effect of music on emotion and memory. ${ }^{32,33}$ Melodies create a sensory expectation by using sequential tones. ${ }^{34}$ Contrary to pitch or instrument perception, melodies connect with inner experiences and memories to reflect a place, pleasure, culture, and experience. ${ }^{35}$ Melodies can also be used as a primary cue when a person tries to remember or identify a song. Therefore, melody recognition appears to have an important connection with music enjoyment among adolescent $\mathrm{CI}$ users. The melodies used in the T-CAMP were generated and isolated, so they could not completely reflect a real-world melody recognition performance. Nevertheless, the connection was still a remarkable and consistent finding, considering the additional relationship between melody recognition and the self-reported measures of lyric comprehension and music listening habits.

Previous studies suggested that training can improve music perception and appraisal. ${ }^{36,37}$ In our study, another important consideration was that the relationship between melody recognition and music enjoyment could not explain whether CI users with good music perception listen to and enjoy music more than they did before or whether CI users who listen to more music might develop better music perception abilities. The lack of a significant correlation between the PDD and the scale could contribute to this discussion. Music exposure is possibly beneficial to the recognition of familiar melodies used

Table 2 Descriptive statistics

\begin{tabular}{|c|c|c|c|c|c|c|}
\hline & \multicolumn{3}{|c|}{ Questionnaire } & \multicolumn{3}{|l|}{ T-CAMP } \\
\hline & Enjoyment & Lyrics & Rate & PDD (ST) & Melody (\%) & Timbre (\%) \\
\hline Mean & 8.14 & 5.46 & 8.32 & 3.44 & 13.89 & 30.21 \\
\hline Median & 9 & 5 & 10 & 2.84 & 8.33 & 27.09 \\
\hline SD & 2.19 & 2.27 & 2.54 & 2.06 & 14.26 & 15.86 \\
\hline Minimum & 3 & 0 & 0 & 0.54 & 0 & 4.17 \\
\hline Maximum & 10 & 10 & 10 & 8.22 & 69.44 & 70.83 \\
\hline 25th percentile & 7 & 5 & 8 & 1.78 & 5.56 & 16.67 \\
\hline 50th percentile & 9 & 5 & 10 & 2.84 & 8.33 & 27.09 \\
\hline 75th percentile & 10 & 6.75 & 10 & 4.59 & 15.97 & 40.63 \\
\hline
\end{tabular}

Abbreviations: PDD, pitch direction discrimination; SD, Standard deviation; ST, semitones; T-CAMP, Turkish Clinical Assessment of Music Perception. 
Music Listening Habits and Music Perception Abilities of Prelingually Deafened Adolescent Cochlear Implant

Table 3 Spearman's correlation coefficients between study variables

\begin{tabular}{|l|l|l|l|l|l|l|l|}
\hline \multicolumn{2}{c|}{} & \multicolumn{2}{l}{ PDD } & \multicolumn{2}{l}{$\begin{array}{l}\text { Timbre } \\
\text { recognition }\end{array}$} & \multicolumn{2}{l|}{ Melody recognition } \\
\cline { 3 - 9 } \multicolumn{2}{c|}{} & $\boldsymbol{r}$ & $\boldsymbol{p}$ & $\boldsymbol{r}$ & $\boldsymbol{p}$ & $\boldsymbol{r}$ & $\boldsymbol{p}$ \\
\hline \multirow{3}{*}{ Questionnaire } & Enjoyment & -0.35 & 0.07 & 0.35 & 0.07 & $0.62^{\mathrm{a}}$ & 0.00 \\
\cline { 2 - 9 } & Rate & -0.23 & 0.23 & 0.25 & 0.21 & $0.45^{\mathrm{a}}$ & 0.02 \\
\cline { 2 - 8 } & Lyrics & -0.12 & 0.56 & 0.18 & 0.36 & $0.43^{\mathrm{a}}$ & 0.02 \\
\hline
\end{tabular}

Abbreviations: PDD, pitch direction discrimination; $r$, Spearman's correlation coefficient.

${ }^{a}$ Statistically significant correlation coefficient.

Table 4 Spearman's correlation coefficients between questionnaire items

\begin{tabular}{|l|l|l|l|}
\hline \multicolumn{2}{|l|}{ Questionnaire items } & $\boldsymbol{r}$ & $\boldsymbol{p}$ \\
\hline Enjoyment & Rate & $0.78^{\mathrm{a}}$ & 0.00 \\
\hline Enjoyment & Lyrics & 0.35 & 0.07 \\
\hline Rate & Lyrics & 0.35 & 0.07 \\
\hline
\end{tabular}

Abbreviation: r, Spearman's correlation coefficient.

astatistically significant correlation coefficient.

in the T-CAMP as a result of the relationship of melody recognition with memory and the effect of learning on central auditory processing. ${ }^{38}$ Pitch perception has a simpler and more peripheral nature than melody recognition and is possibly more related to auditory abilities when $\mathrm{CI}$ is considered. This possibility is also supported by the fact that $\mathrm{Cl}$ users with good residual acoustic hearing benefit the most in pitch perception tasks, and their performance is similar to that of subjects with normal hearing. ${ }^{28}$ Therefore, music exposure and training could be beneficial to central auditory processing tasks, such as melody recognition.

The timbre recognition of the $\mathrm{CI}$ users was relatively poor as a result of the poor temporal fine structure information conveyed by the $\mathrm{CI}$ processor. Timbre recognition does not improve with exposure. ${ }^{39}$ The limitation of timbre recognition can also restrict the relationship between music listening habits and timbre recognition, as observed in our study.

\section{Music Listening Habits}

The group mean for the enjoyment item was close to "a few times in a week," but some participants marked this question 0 even when they had better-than-average T-CAMP scores. This observation emphasized the importance of an individually crafted approach to music-related training in clinical settings. Some of the subjects mentioned that they never had any interest in listening to music, and this phenomenon could be a natural consequence of being prelingually deafened at a young age. Some subjects probably never had an opportunity to perceive music as something enjoyable or natural. However, the enjoyment and listening rates of our subjects were better than that reported in many previous studies. Previous studies used various questionnaires and scales, and our study employed an in-house test; hence, previous and present results might not be directly compared. The lack of studies on prelingually deafened adolescents or young adults also limits the possibility of comparison. Thus far, only Moran et $\mathrm{al}^{40}$ evaluated the music listening habits of prelingually deafened adult $\mathrm{CI}$ users. They found that the mean amount of music listening among subjects is close to "sometimes," and enjoyment is better than "neutral." However, the average chronological age (51.19 years) and ageat-implantation (47.29 years) of the participants in our study were well above our study sample. Therefore, the difference in enjoyment and habit scores in our study could be a result of the younger age of our participants, in addition to our use of a different scale.

The average self-reported lyric comprehension score was close to the midpoint of the scale. In modern music, lyrics are usually accompanied with other instruments, and this complex structure can make auditory scene analysis difficult. This difficulty may in turn increase if subjects are unfamiliar with a song, considering the effect of the masking of other instruments in spectral and temporal domains. However, the important point in our study was that no statistically significant correlation was observed between lyric comprehension and music enjoyment. This finding supported previous reports on the positive effect of pre- and postimplantation music experience on music enjoyment measures ${ }^{12}$ when they are evaluated in conjunction with statistically significant and strong correlation between enjoyment and rate items. The frequency of listening to music of the subjects who enjoyed doing it was higher than that of the subjects who did not enjoy this activity. However, the possible influence of music exposure on enjoyment should still be considered.

\section{Limitations}

The most important limitation of our study was the scale used. None of the previously used and validated questionnaires or scales were adapted for our culture and language; therefore, a simple three-item scale was chosen in our study to minimize measurement errors. Despite this limitation, correlations between scale items were similar to those in previous studies, and a significant correlation coefficient between music enjoyment and listening habits was observed.

\section{Conclusion}

The present study shows that melody recognition abilities are significantly related to music enjoyment and listening habits in prelingually deafened adolescent $\mathrm{CI}$ users. This relationship is possibly bidirectional. As music exposure 
increases the melody recognition abilities of CI users, melody recognition enhances because of more listening time and enjoyment. Being prelingually deafened does not prevent $\mathrm{CI}$ users from enjoying and listening to music, and this finding is important for adolescents who are in the critical period of development between childhood and adulthood.

\section{Ethical Approval}

All procedures performed in studies involving human participants were in accordance with the ethical standards of the institutional and/or national research committee and with the 1964 Helsinki Declaration and its later amendments or comparable ethical standards.

\section{Conflict of Interest}

All authors declare there are no conflicts of interest.

\section{References}

1 Juslin PN, Liljeström S, Västfjäll D, Lundqvist L-O. How does music evoke emotions? Exploring the underlying mechanisms. In: Juslin PN, Sloboda JA, eds. Series in Affective Science. Handbook of Music and Emotion: Theory, Research, Applications. Oxford, UK: Oxford University Press; 2010:605-642

2 Lassaletta L, Castro A, Bastarrica M, et al. Does music perception have an impact on quality of life following cochlear implantation? Acta Otolaryngol 2007;127(07):682-686

3 Geller K, Lansing CR. Melodic, rhythmic, and timbral perception of adult cochlear implant users. J Speech Hear Res 1991;34(04):916-920

4 Leal MC, Shin YJ, Laborde M-L, et al. Music perception in adult cochlear implant recipients. Acta Otolaryngol 2003;123(07):826-835

5 Drennan WR, Rubinstein JT. Music perception in cochlear implant users and its relationship with psychophysical capabilities. J Rehabil Res Dev 2008;45(05):779-789

6 Nimmons GL, Kang RS, Drennan WR, et al. Clinical Assessment of Music Perception in cochlear implant listeners. Otol Neurotol 2008;29(02):149-155

7 Won JH, Drennan WR, Kang RS, Rubinstein JT. Psychoacoustic abilities associated with music perception in cochlear implant users. Ear Hear 2010;31(06):796-805

8 Gfeller K, Knutson JF, Woodworth G, Witt S, DeBus B. Timbral recognition and appraisal by adult cochlear implant users and normal-hearing adults. J Am Acad Audiol 1998;9(01):1-19

9 Gfeller K, Witt S, Woodworth G, Mehr MA, Knutson J. Effects of frequency, instrumental family, and cochlear implant type on timbre recognition and appraisal. Ann Otol Rhinol Laryngol 2002; 111(04):349-356

10 Gfeller K, Christ A, Knutson JF, Witt S, Murray KT, Tyler RS. Musical backgrounds, listening habits, and aesthetic enjoyment of adult cochlear implant recipients. J Am Acad Audiol 2000;11(07):390-406

11 Mirza S, Douglas SA, Lindsey P, Hildreth T, Hawthorne M. Appreciation of music in adult patients with cochlear implants: a patient questionnaire. Cochlear Implants Int 2003;4(02):85-95

12 Gfeller K, Oleson J, Knutson JF, Breheny P, Driscoll V, Olszewski C. Multivariate predictors of music perception and appraisal by adult cochlear implant users. J Am Acad Audiol 2008;19(02):120-134

13 Philips B, Vinck B, De Vel E, et al. Characteristics and determinants of music appreciation in adult CI users. Eur Arch Otorhinolaryngol 2012;269(03):813-821

14 Wright R, Uchanski RM. Music perception and appraisal: cochlear implant users and simulated cochlear implant listening. J Am Acad Audiol 2012;23(05):350-365, quiz 379

15 Drennan WR, Oleson JJ, Gfeller K, et al. Clinical evaluation of music perception, appraisal and experience in cochlear implant users. Int J Audiol 2015;54(02):114-123
16 Miranda D. The role of music in adolescent development: much more than the same old song. Int J Adolesc Youth 2013;18:5-22

17 Brown JD, Bobkowski PS. Older and newer media: patterns of use and effects on adolescents' health and well-being. J Res Adolesc 2011;21:95-113

18 Chapman PL, Mullis RL. Adolescent coping strategies and selfesteem. Child Study J 1999;29:69-69

19 Hargreaves DJ. Music and adolescent identity AU - North, Adrian C. Music Educ Res 1999;1:75-92

20 North AC, Hargreaves DJ, O'Neill SA. The importance of music to adolescents. Br J Educ Psychol 2000;70(Pt 2):255-272

21 Johnson JK, Louhivuori J, Siljander E. Comparison of well-being of older adult choir singers and the general population in Finland: a case-control study. Music Sci 2017;21(02):178-194

22 Ekholm O, Juel K, Bonde LO. Associations between daily musicking and health: results from a nationwide survey in Denmark. Scand J Public Health 2016;44(07):726-732

23 Tambs K. Moderate effects of hearing loss on mental health and subjective well-being: results from the Nord-Trøndelag Hearing Loss Study. Psychosom Med 2004;66(05):776-782

24 Li CM, Zhang X, Hoffman HJ, Cotch MF, Themann CL, Wilson MR. Hearing impairment associated with depression in US adults, National Health and Nutrition Examination Survey 2005-2010. JAMA Otolaryngol Head Neck Surg 2014;140(04):293-302

25 Driscoll VD, Welhaven AE, Gfeller K, Oleson J, Olszewski CP. Music perception of adolescents using electroacoustic hearing. Otol Neurotol 2016;37(02):e141-e147

26 Jung KH, Won JH, Drennan WR, et al. Psychoacoustic performance and music and speech perception in prelingually deafened children with cochlear implants. Audiol Neurotol 2012;17(03): 189-197

27 Kang R, Nimmons GL, Drennan W, et al. Development and validation of the University of Washington Clinical Assessment of Music Perception test. Ear Hear 2009;30(04):411-418

28 Yüksel M, Meredith MA, Rubinstein JT. Effects of low frequency residual hearing on music perception and psychoacoustic abilities in pediatric cochlear implant recipients. Front Neurosci 2019;13:924

29 Yüksel M, Çiprut A. Music and psychoacoustic perception abilities in cochlear implant users with auditory neuropathy spectrum disorder. Int J Pediatr Otorhinolaryngol 2020;131:109865

30 Abascal E, Rada VDD. Analysis of 0 to 10 -point response scales using factorial methods: a new perspective. Int J Soc Res Methodol 2014; 17:569-584

31 Scherpenzeel A. Why use 11-point scales. Swiss Household Panel 2002;9:2008

32 Hoshino E. The feeling of musical mode and its emotional character in a melody. Psychol Music 1996;24:29-46

33 Jäncke L. Music, memory and emotion. J Biol 2008;7(06):21-21

34 Marmel F, Tillmann B, Delbé C. Priming in melody perception: tracking down the strength of cognitive expectations. J Exp Psychol Hum Percept Perform 2010;36(04):1016-1028

35 Aldridge D, Aldridge G. Melody in Music Therapy: A Therapeutic Narrative Analysis. London, UK: Jessica Kingsley Publishers; 2008

36 Looi V, She J. Music perception of cochlear implant users: a questionnaire, and its implications for a music training program. Int J Audiol 2010;49(02):116-128

37 Looi V, Gfeller K, Driscoll V. Music appreciation and training for cochlear implant recipients: a review. Semin Hear 2012;33(04): 307-334

38 Weihing J, Chermak GD, Musiek FE. Auditory training for central auditory processing disorder. Semin Hear 2015;36(04): 199-215

39 Gfeller K, Jiang D, Oleson JJ, Driscoll V, Knutson JF. Temporal stability of music perception and appraisal scores of adult cochlear implant recipients. J Am Acad Audiol 2010;21(01):28-34

40 Moran M, Rousset A, Looi V. Music appreciation and music listening in prelingual and postlingually deaf adult cochlear implant recipients. Int J Audiol 2016;55(Suppl 2):S57-S63 